\title{
Uma história contestada: a História Medieval na Base Nacional Comum Curricular (2015-2017)
}

\author{
A contested history: Medieval History on the National Curricular Common Base \\ (2015-2017)
}

\begin{abstract}
RESUMO: Os debates sobre a Base Nacional Comum Curricular (BNCC) fizeram sobressair posicionamentos que propõem restrições ao estudo da antiguidade e do medievo na educação básica, postura que mobilizou medievalistas brasileiros no intuito de justificar a permanência da área no ensino escolar e de iniciar uma reflexão sobre o ensino de história medieval nas escolas. A BNCC é o documento que irá nortear todos os níveis da educação no Brasil, por isso este artigo discute a presença da Idade Média nas três versões da BNCC e apresenta alguns apontamentos acerca da inserção do medievo na educação escolar.
\end{abstract}

PALAVRAS-CHAVE: BNCC. História Medieval. Ensino de história.

ABSTRACT: The debates about the National Curricular Common Base (BNCC) have highlighted positions that propose restrictions on the study of antiquity and the Middle Ages in basic education, a position that mobilized Brazilian medievalists in order to justify the permanence of the area in school education and to initiate a reflection on the teaching of medieval history in schools. The BNCC is the document that will guide all levels of education in Brazil, so this article discusses the presence of the Middle Ages in the three versions of BNCC and present some notes about the insertion of the Middle Ages in school education.

KEYWORDS: BNCC. Medieval History. History teaching.

\footnotetext{
* Professor Adjunto da Universidade Federal do Oeste do Pará (UFOPA), Santarém, PA, Brasil. Doutor em História pela Universidade Federal Fluminense (UFF). E-mail: dougmotahistoria@gmail.com.

http://orcid.org/0000-0002-7197-7930
} 


\section{Introdução}

Uma série de mudanças marca o cenário da educação brasileira nos últimos anos e, entre elas, a Base Nacional Comum Curricular (BNCC) configura-se como uma das mais importantes e controversas medidas. Documento de "caráter normativo que define o conjunto orgânico e progressivo de aprendizagens essenciais que todos os alunos devem desenvolver ao longo das etapas e modalidades da Educação Básica” (BRASIL, 2017b, p. 7), a Base foi apresentada, discutida, revisada e aprovada num cenário de profunda polarização política, que passa pelo segundo processo de impeachment presidencial desde a redemocratização dos anos 1980, pela reconfiguração dos partidos políticos e dos movimentos sociais, por crescentes denúncias de corrupção envolvendo diferentes esferas da política nacional e, no plano da educação, pelo avanço de projetos que interferem no exercício da docência, como o projeto Escola Sem Partido.

Figura 1 - Marcos legais e políticas decorrentes da BNCC.

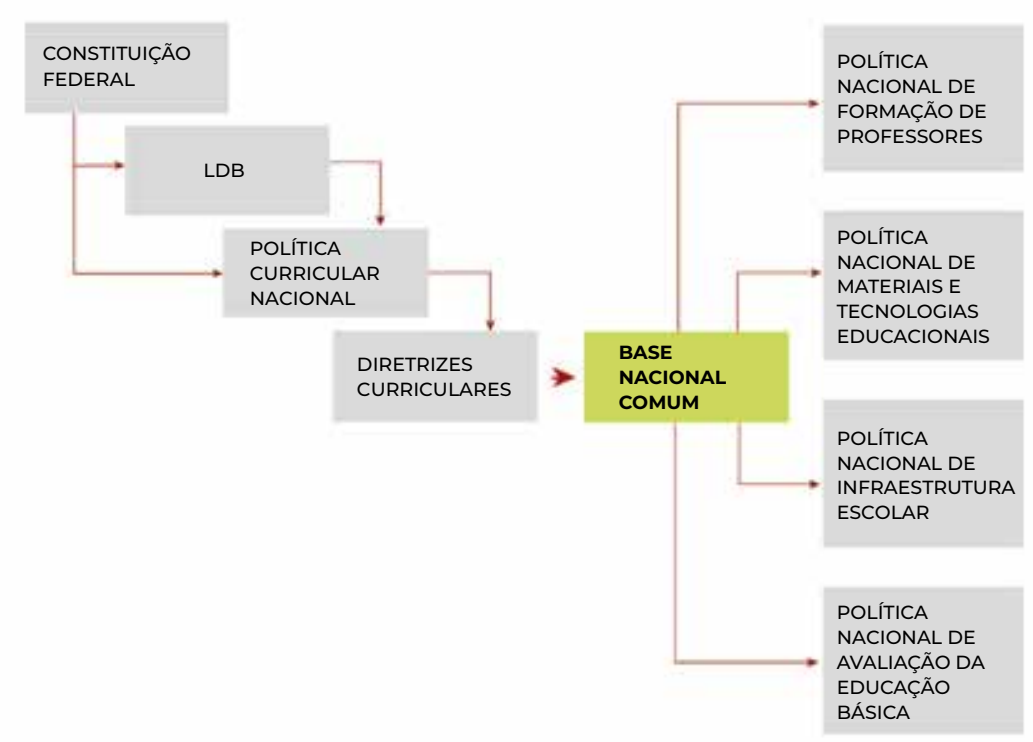

Fonte: Brasil (2016, p. 26).

A BNCC, lançada em sua primeira versão pelo Ministério da Educação (MEC) em setembro de 2015, está prevista desde a Constituição Federal de 1988, através do artigo 210 (BRASIL, 2017a), e foi reafirmada na Lei de Diretrizes e Bases (Lei 9.394/96), nos Parâmetros Curriculares Nacionais, nas Diretrizes Curriculares Nacionais da Educação Básica e no Plano Nacional de Educação. Conforme o texto da BNCC, decorrem da Base políticas como: Política Nacional de Formação de Professores; Política Nacional de Materiais e Tecnologias Educacionais; Política Nacional de Avaliação da Educação Básica; e Política Nacional de Infraestrutura Escolar.

Durante o primeiro período de consulta pública, previsto para ocorrer entre outubro de 2015 e março de 2016, a primeira versão mobilizou mais de 12 milhôes de contribuições (BRASIL, 2017 b, p. 5), todavia dividiu os profissionais da educação em, ao menos, dois grandes grupos: os que são contrários à existência de uma base nacional e aqueles que são favoráveis ao currículo comum nacional. Nesse cenário de embates, a Base foi alvo de inúmeras críticas, em especial, relacionadas ao componente curricular História, o último componente a ser divulgado para consulta. Além 
dos posicionamentos de historiadores atuantes na Educação Básica e, principalmente, no Ensino Superior, houve também manifestações contrárias do ex-ministro da educação, Renato Janine Ribeiro, e de outras personalidades, alcançando publicidade em jornais, revistas e sites de ampla divulgação como O Estado de São Paulo, Folha de São Paulo e O Globo. Sem pretender recuperar o conjunto desses apontamentos, assinalam-se algumas críticas relativas à primeira versão.

Ao considerar o documento como um todo, a Associação Nacional de Pós-Graduação e Pesquisa em Educação (ANPEd) e a Associação Brasileira de Currículo (ABdC), através de Ofício em novembro de 2015, publicaram uma avaliação da Base classificando-a como "problemática e imprópria para as finalidades a que se destina" (ANPEd; ABdC, 2015, p. 1). O mesmo Ofício denunciou a posição do MEC na condução dos debates, indicando que o Ministério tem privilegiado um "projeto unificador e mercadológico na direção que apontam as tendências internacionais de uniformização/centralização curricular + testagem em larga escala + responsabilização de professores e gestores" (ANPEd; $\mathrm{ABdC}, 2015$, p. 2). O documento colocou-se contrário à metodologia de construção da Base, indicando que a mesma foi guiada pela pressa, com debates minimizados, participações reduzidas a seminários de audiência muda e consultas eletrônicas para a legitimação de um processo sem roteiro definido.

Especificamente sobre os conteúdos de História, em 23 de dezembro de 2015, a Associação Nacional de Pesquisadores e Professores de História das Américas (ANPHLAC) apresentou suas críticas argumentando que a Base assume uma perspectiva que não contempla as conexôes e/ou confrontos entre os espaços europeu e americano. Também no mês de dezembro foi publicado o documento História da América e BNCC, contando com a assinatura de onze professores universitários do Rio de Janeiro. O documento criticou a Base afirmando que grande parte da história da humanidade não foi contemplada pelo texto, estando a história da Antiguidade e da Idade Média ausente, e a história da Idade Moderna e da Idade Contemporânea sub-representadas. As críticas avançam com a afirmação de que a Europa moderna aparece em função das "conquistas" da América e da África e com a defesa de que "a exclusão do conhecimento dos processos históricos europeus desde a antiguidade até o período da expansão ultramarina portuguesa [...] nos deixará sem ferramentas para sua crítica" (GARCIA et al., 2015).

Em fevereiro de 2016, o GT de História da África da Anpuh e a Associação Brasileira de Estudos Africanos (ABE-África) manifestaram-se contrários à Base. Segundo a nota coletiva, a primeira versão parece desconsiderar os conhecimentos apresentados por uma historiografia contemporânea internacional, inclusive africana e brasileira sobre África, crítica à perspectiva eurocêntrica, sobretudo no que se refere à abordagem das sociedades africanas que privilegia as noções de estado e formações políticas centralizadas e hierarquizadas. A nota apontou que, ao excluir algumas temporalidades e privilegiar os processos históricos localizados entre os séculos XVI e XIX, a Base promove uma visão reducionista da História da África em duas dimensóes relacionadas, geográfica e temática, tratando da África pelas relações estabelecidas por meio dos nexos com a História do Brasil, isto é, uma África restrita aos espaços de intervenção de portugueses e brasileiros e, notadamente, ao tema do tráfico de escravos (ANPUH; ABE-África, 2016).

Outros manifestos, notas, cartas e textos diversos poderiam ser arrolados a fim de expor um levantamento detalhado das críticas à primeira versão da BNCC, assim como um estudo mais aprofundado demandaria considerar as manifestações em apoio ao texto da Base, tanto ao documento em geral como no item relativo ao ensino de história ${ }^{2}$. Ambas as vias se afastam 
do interesse do presente texto, visto que ele procura apresentar as principais críticas ao texto da primeira versão da Base com o objetivo de demonstrar, como ponto de partida, que a polêmica em torno da História Antiga (TACLA; LIMA, 2016; LEITE, 2017) e da História Medieval foi apenas um dos desafios lançados à versão preliminar do documento. Dito isso, cabe considerar a referida polêmica que consiste, basicamente, na ausência dos conteúdos de Antiga e Medieval na proposta, afinal, como ressalta Flávia Caimi: "a tarefa de construir uma base curricular comum para o conhecimento histórico escolar implica trazer ao âmbito do debate público as disputas em torno de ideias quanto ao que, do passado, é válido e legítimo ensinar às novas gerações” (CAIMI, 2015 apud CAIMI, 2016, p. 88).

\section{A História Medieval na BNCC}

O documento está centrado na História do Brasil $^{3}$ e a versão caracteriza-se pelo significativo esforço de romper com uma narrativa histórica de viés eurocêntrico, na qual o Brasil surge no período das Navegaçóes, e pela promoção de medidas que retiram a história indígena e afro-brasileira das margens da História escolar. Isto é, a Base propõe-se a efetivar a aplicação das Leis 10.639/03 e 11.645/08. Nas palavras de Caimi:

Tratando-se de uma primeira versão da Base Nacional, o documento não se mostrou isento de lacunas e inconsistências, aspecto que foi claramente assumido pelos seus autores e também ensejou um largo período de consulta pública. Não obstante essas naturais dificuldades, a proposta então apresentada mostrava avanços ao romper com modelos explicativos pautados num código disciplinar centenário, que já não responde às demandas e desafios que se apresentam à sociedade brasileira na contemporaneidade; ao propor a análise histórica a partir de diferentes escalas espaço-temporais e de diversos pontos de observação, deslocando o olhar de uma perspectiva essencialmente eurocêntrica e da ambição de estudar "toda a história"; ao superar a periodização quadripartite da história europeia, eivada de uma ótica temporal totalizante e de uma ortodoxia cronológica, pautada pela ideia de progresso linear; ao propor a história do Brasil como força mobilizadora da análise histórica, dando centralidade à noção de sujeito e à formação da consciência histórica, ao mesmo tempo em que estabelece nexos e articulaçóes com as histórias africanas, americanas, asiáticas e europeias; ao priorizar o tratamento das diversidades étnicas e culturais, notadamente as que dizem respeito às leis 10.639/2003 e 11.645/2008; ao propor a mobilização de procedimentos de investigação e problematização histórica, em detrimento de práticas verbalistas e de memorização, pautadas em aulas expositivas e na centralidade do professor como protagonista dos processos de ensinar e aprender (CAIMI, 2015 apud CAIMI, 2016, p. 90).

A versão apresenta um “enfoque predominante” (não exclusivo) para cada ano escolar, o qual se encontra traduzido nos seguintes títulos: 
Quadro 1 - Enfoques predominantes para a área de História.

\begin{tabular}{|c|c|c|c|}
\hline Ano & Enfoque Predominante & Ano & Enfoque Predominante \\
\hline \multicolumn{4}{|c|}{ Ensino Fundamental } \\
\hline 1o ano & Sujeitos e Grupos sociais & 6o ano & $\begin{array}{c}\text { Representaçôes, sentidos e significados } \\
\text { do tempo histórico }\end{array}$ \\
\hline 2o ano & Grupos sociais e Comunidades & 7o ano & Processos e Sujeitos \\
\hline 3o ano & Comunidades e outros lugares de vivência & 8o ano & Análise de processos históricos \\
\hline 4o ano & Lugares de vivência e relações sociais & 9o ano & Análise de processos históricos \\
\hline 5o ano & Mundos brasileiros & & \\
\hline \multicolumn{4}{|c|}{ Ensino Médio } \\
\hline 1o ano & \multicolumn{3}{|c|}{ Mundos ameríndios, africanos e afro-brasileiros } \\
\hline 2o ano & \multicolumn{3}{|c|}{ Mundos americanos } \\
\hline 3o ano & \multicolumn{3}{|c|}{ Mundos europeus e asiáticos } \\
\hline
\end{tabular}

Fonte: Elaborado pelo autor com base em Brasil (2015, p. 243).

De acordo com essa distribuição, para o Ensino Fundamental, é apenas no 6o ano que aparece menção à História Antiga e Medieval, nos itens: "CHHI6FOA66: Conhecer e reconhecer diversas maneiras de contagem e registro do tempo - calendários e formas consagradas -, dos astecas, dos maias, dos egípcios, dos diferentes povos indígenas brasileiros, entre outros, discutindo usos e adequações"; "CHHI6FOA71: Conhecer e problematizar as diferentes formas de periodização dos processos históricos tais como o modelo quadripartite francês (Idade Antiga, Idade Média, Idade Moderna e Idade Contemporânea), identificando como o Brasil se insere nesta periodização"; e "CHHI6FOA072: Identificar e discutir características, pessoas, instituições, ideais e acontecimentos relativos a cada um desses períodos históricos: Idade Antiga, Idade Média, Idade Moderna e Idade Contemporânea” (BRASIL, 2015, p. 251). As demais referências aos termos "Antiga", "Antiguidade", "Medieval” e "Idade Média" aparecem todas nos componentes Física, Química e Filosofia.

Em linhas gerais, a primeira versão da Base parece encarar os estudos da pré e proto-histórias, assim como das sociedades pré-modernas, em especial da Antiguidade e do Medievo, como conteúdos eurocêntricos, distantes da realidade dos alunos brasileiros e, consequentemente, de importância secundária no currículo de História, ficando apenas a cargo do docente optar ou não pela introdução dessas sociedades nas aulas. Ao buscar romper com a visão quadripartite de história, a versão acaba por excluir a Antiguidade, o Medievo e parte considerável do mundo moderno, centrando a atenção no Brasil e tendo como ponto de partida o início da colonização. Esse impasse expressa uma das questóes centrais colocadas à área de História Antiga e História Medieval no Brasil, isto é, considerando pertinente a crítica ao modelo quadripartite, como romper 
com uma visão eurocêntrica da História reafirmando o estudo das sociedades antigas e medievais no currículo obrigatório? Antes de propor apontamentos sobre essa questão, cabe observar as mudanças presentes nas versões seguintes da BNCC.

No dia 3 de maio de 2016, foi divulgada pelo Ministério da Educação a segunda versão da Base Nacional Comum Curricular. Enquanto a primeira versão não identificava os envolvidos na elaboração da Base, a segunda apresenta os nomes nas primeiras páginas do documento. Relacionados ao componente História, constam: Ensino Fundamental (Anos Iniciais): Tatiana Garíglio Clark Xavier (MG/Consed), Maria da Guia de Oliveira Medeiros (RN/Undime), Margarida Maria Dias de Oliveira (UFRN) e Leila Soares de Souza Perussolo (RR/Undime); Ensino Fundamental (Anos Finais): Marinelma Costa Meireles (MA/Consed), Rilma Suely de Souza Melo (PB/Undime) e Giovani José da Silva (UNIFAP); e Ensino Médio: Reginaldo Gomes da Silva (AP/Consed), Antônio Daniel Marinho Ribeiro (AL/Consed) e Leandro Mendes Rocha (UFG).

São ainda apresentados nomes de profissionais que foram responsáveis pelo envio de pareceres críticos, como os professores Renilson Rosa Ribeiro, Universidade Federal de Mato Grosso; Luís Fernando Cerri, Universidade Estadual de Ponta Grossa; Marieta de Moraes Ferreira, Universidade Federal do Rio de Janeiro; Marcelo de Souza Magalhães, Universidade Federal do Estado do Rio de Janeiro; Martha Campos Abreu, Universidade Federal Fluminense; Sandra Regina Ferreira de Oliveira, Universidade Estadual de Londrina; Pedro Paulo Abreu Funari, Universidade Estadual de Campinas; e Flavia Eloisa Caimi, Universidade de Passo Fundo.

Quadro 2 - Profissionais ligados à elaboração da $1^{\mathrm{a}}$ e da $2^{\mathrm{a}}$ versão da BNCC-História.

\begin{tabular}{|c|c|c|c|}
\hline & Consed & Undime & Universidades \\
\hline \multirow{7}{*}{ 1a versão } & $\begin{array}{c}\text { Tatiana Garíglio Clark Xavier } \\
(\mathrm{MG})\end{array}$ & $\begin{array}{l}\text { Maria da Guia de Oliveira } \\
\text { Medeiros (RN) }\end{array}$ & Giovani Jose da Silva (UNIFAP) \\
\hline & $\begin{array}{c}\text { Marinelma Costa Meireles } \\
\text { (MA) }\end{array}$ & $\begin{array}{l}\text { Rilma Suely de Souza Melo } \\
\qquad(\mathrm{PB})\end{array}$ & Leandro Mendes Rocha (UFG) \\
\hline & $\begin{array}{l}\text { Reginaldo Gomes da Silva } \\
\qquad(\mathrm{AP})\end{array}$ & $\begin{array}{l}\text { Leila Soares de Souza } \\
\text { Perussolo (RR) }\end{array}$ & $\begin{array}{l}\text { Margarida Maria Dias de } \\
\text { Oliveira (UFRN) }\end{array}$ \\
\hline & $\begin{array}{c}\text { Antônio Daniel Marinho } \\
\text { Ribeiro (AL) }\end{array}$ & & Marco Antônio da Silva (USP) \\
\hline & $\begin{array}{l}\text { Leila Soares de Souza } \\
\text { Perussolo (RR) }\end{array}$ & & Itamar Freitas (UnB) \\
\hline & & & Mauro Cézar Coelho (UFPA) \\
\hline & Consed & Undime & Universidades \\
\hline \multirow{4}{*}{ 2⿳亠口了 versão } & $\begin{array}{l}\text { Tatiana Garíglio Clark Xavier } \\
\text { (MG) }\end{array}$ & $\begin{array}{l}\text { Maria da Guia de Oliveira } \\
\text { Medeiros (RN) }\end{array}$ & Giovani Jose da Silva (UNIFAP) \\
\hline & $\begin{array}{c}\text { Marinelma Costa Meireles } \\
\text { (MA) }\end{array}$ & $\begin{array}{l}\text { Rilma Suely de Souza Melo } \\
\qquad(\mathrm{PB})\end{array}$ & Leandro Mendes Rocha (UFG) \\
\hline & $\begin{array}{l}\text { Reginaldo Gomes da Silva } \\
\text { (AP) }\end{array}$ & $\begin{array}{l}\text { Leila Soares de Souza } \\
\text { Perussolo (RR) }\end{array}$ & $\begin{array}{c}\text { Margarida Maria Dias de Oliveira } \\
\text { (UFRN) }\end{array}$ \\
\hline & $\begin{array}{c}\text { Antônio Daniel Marinho } \\
\text { Ribeiro (AL) }\end{array}$ & & \\
\hline
\end{tabular}

Fonte: Elaborado pelo autor com base em Brasil (2016, p. 9). 
Constata-se que houve uma redução ${ }^{4}$ da equipe envolvida na elaboração da segunda versão e que uma das principais críticas ao primeiro documento - a ausência de membros de diferentes áreas da História — não foi atendida. Não obstante, a distribuição da equipe de História seguiu o padrão adotado para as demais áreas e, ao considerar o conjunto de pareceristas, nota-se uma leve diversificação do grupo de assessoramento, porém a equipe permaneceu concentrando professores do campo de Ensino de História e História do Brasil.

Relativo ao conteúdo de História, observa-se uma significativa variação entre as versóes, reorientação, quiçá, melhor expressa através da manchete do jornal Folha de São Paulo: "Nova versão da base nacional curricular traz de volta história da Europa" (CANCIAN, 2016). Além disso, a segunda versão também se destaca como uma resposta aos questionamentos lançados à primeira versão, problemáticas de apelo popular e midiático que apontavam, por exemplo, o viés ideológico do documento, crítica que pode ser ilustrada pelo tema da "ideologia de gênero" que estaria direcionando o currículo de História. Nesse cenário, o relatório da Australian Curriculum, Assessment and Reporting Authority (ACARA), produzido sobre a segunda versão, afirma sobre o componente curricular História: "Os autores estão de parabéns por terem desenvolvido um curso de história tão bem equilibrado para todos os anos e que não favorece nenhum posicionamento ideológico" (MCASKILL, 2016, p. 5).

A nova versão não apresenta uma reflexão sobre a questão do eurocentrismo; negros e índios voltam a um lugar periférico; a história do Brasil perde a centralidade para voltar a ficar isolada da história geral; há um enfoque cronológico e uma manutenção da grande narrativa centrada na matriz europeia. Em linhas gerais, há um regresso a um conteúdo que se pode classificar de tradicional ou conservador. Caimi, por exemplo, tece duras críticas à versão que corroboram a perspectiva conservadora da BNCC 2016:

Trata-se de uma proposta que se refugia nos conteúdos convencionais e canônicos, tomando a cronologia linear como eixo central do discurso histórico, ou seja, desconsidera os postulados, princípios e proposiçóes oriundos da pesquisa acadêmica nacional e estrangeira dos últimos trinta anos, representando um flagrante e lamentável retrocesso (CAIMI, 2016, p. 10-11).

Do mesmo modo, Nilton Pereira e Mara Rodrigues afirmam que a segunda versão da BNCC, relativa ao componente curricular história, consiste em um retrocesso por diferentes razôes:

[A] segunda versão optou por, justamente, retornar à ênfase na lista de conteúdos, relatando objetivos "clássicos" do ensino de história, deixando de renovar tanto o campo teórico da escrita da história quanto as competências intelectuais [...]. A opção por essa lista tornou a BNCC muito próxima de uma história sem corpo e sem política, uma vez que estabelece conteúdos considerados "canônicos" e obrigatórios ao conhecimento dos estudantes e das novas geraçôes. Essa ideia supôe que determinados conteúdos são indispensáveis, mas, ao mesmo tempo, não problemáticos e com pouco ou nenhum sentido em relação ao tempo presente. [...] [A] segunda versão supõe a existência de uma dominância da história europeia, cujo sentido unificado engloba e unifica a diversidade de etnias, culturas, grupos e atores sociais. [...] [A] configuração da segunda versão da BNCC, a despeito das pretensóes mencionadas, parte do princípio de que é possível, tanto teórica quanto quantitativamente, ensinar "toda a história", ou seja, o conjunto das experiências humanas. Tal concepção acaba por dificultar a compreensão da complexidade da escrita da história pelos estudantes, pois desconhece a arte e a política do recorte como elemento central na elaboração de qualquer história e de qualquer currículo. [...] [H]á uma deliberada invisibilidade 
das mulheres como agentes sociais e históricos até o momento em que conquistam direitos políticos. Outras orientações sexuais, então, sequer aparecem como possibilidades efetivas de identidade, constituindo-se como experiência humana de um "outro" a ser anexado, mais do que integrado, à sociedade e à história (PEREIRA; RODRIGUES, 2018, p. 9-10).

Tal orientação "conteudista” manifesta-se, por exemplo, na incorporação da História Antiga e Medieval no ensino fundamental através da ênfase na Antiguidade Clássica e num medievo centrado no Ocidente medieval.

Quadro 3 - Conhecimentos históricos relacionados à Idade Média na $2^{\text {a }}$ versão da BNCC.

\begin{tabular}{|c|c|}
\hline Ano & Conhecimentos Históricos \\
\hline \multirow{14}{*}{ 6o ano } & $\begin{array}{l}\text { (EF06HI16) Reconhecer as origens do Islamismo na Península Arábica no século } \\
\text { VIII. }\end{array}$ \\
\hline & $\begin{array}{l}\text { (EF06HI17) Compreender a desestruturação do Império Romano e a formação do } \\
\text { mundo medieval na Europa. }\end{array}$ \\
\hline & (EF06HI19) Identificar aspectos do conceito de feudalismo. \\
\hline & $\begin{array}{l}\text { (EF06HI20) Identificar a fragmentação do poder político e a primazia cultural e } \\
\text { política da Igreja católica. }\end{array}$ \\
\hline & $\begin{array}{l}\text { (EF06HI21) Classificar a estrutura da sociedade feudal definida a partir de três } \\
\text { ordens, dos oratores, bellatores e laboratores, representadas pelas figuras do sacerdote, } \\
\text { do cavaleiro e do camponês. }\end{array}$ \\
\hline & (EF06HI22) Identificar o papel do comércio e das cidades na Idade Média. \\
\hline & $\begin{array}{l}\text { (EF06HI23) Identificar aspectos de manifestações culturais e artísticas do mundo } \\
\text { medieval, destacando a construção das catedrais, de castelos e o nascimento da } \\
\text { Universidade. }\end{array}$ \\
\hline & $\begin{array}{l}\text { (EF06HI24) Analisar e problematizar o conceito de Idade Média como periodização } \\
\text { da História Universal. }\end{array}$ \\
\hline & $\begin{array}{l}\text { (EF06HI25) Estabelecer as relações do mundo medieval com o mundo árabe, com o } \\
\text { Império Otomano e com as populações judias. }\end{array}$ \\
\hline & $\begin{array}{l}\text { (EF06HI26) Compreender o papel da biblioteca de Alexandria, das Cruzadas e da } \\
\text { presença de judeus e árabes na Península Ibérica. }\end{array}$ \\
\hline & $\begin{array}{l}\text { (EF06HI27) Conhecer marcos fundamentais das Histórias Antiga e Medieval, } \\
\text { incluindo contraposições, conexões e trocas que se estabeleceram entre “Ocidente” e } \\
\text { "Oriente" ao longo desses séculos (cerca de } 3 \text { mil a.C. a fins do século XV). }\end{array}$ \\
\hline & $\begin{array}{l}\text { (EF06HI28) Produzir textos que discorram sobre o desenvolvimento dessas civiliza- } \\
\text { ções e sociedades. }\end{array}$ \\
\hline & (EF06HI29) Identificar diferentes fontes de conhecimento sobre as cidades medievais. \\
\hline & (EF06HI30) Compreender a noção de "era cristã". \\
\hline
\end{tabular}

Fonte: Elaborado pelo autor com base em Brasil (2016, p. 466, 468, 470, 472). 
Como se observa no quadro 3, a segunda versão diferencia-se da primeira por recuperar de forma bem expressiva a História Medieval. Conforme o texto da Base, o aluno inicia o estudo da História Antiga no 4o ano, ainda no Ensino Fundamental - Anos Iniciais, abordando temas como o surgimento da agricultura, da escrita e das cidades; em seguida, no 5o ano, concentra-se nas "primeiras civilizações"; ao chegar ao Ensino Fundamental - Anos Finais, no 6o ano, tem o conteúdo distribuído entre Grécia, Roma e Idade Média. Acrescenta-se que, para o Ensino Médio, a versão prevê três unidades curriculares que não contemplam a antiguidade e o medievo: a primeira "apresenta um quadro abrangente da história das Américas, interligando não apenas a história da América Hispânica à América Portuguesa, mas também a relação dos processos históricos dessas Américas com a América inglesa”; a segunda "apresenta um quadro da história mundial do Século XX, a começar pelo processo de queda dos sistemas coloniais em África e Ásia, culminando com a conformação do processo de globalização"; e a terceira "dedica-se ao Brasil republicano e, especialmente, ao processo de modernização que levou a formação de um país urbano, industrial e democrático" (BRASIL, 2016, p. 631).

Acerca do medievo, a Base centra-se na Europa medieval, particularmente no Ocidente medieval, ainda que a justificativa para essa orientação não fique explícita. Apesar dessa tendência, o texto destaca o surgimento do islã e a relação da Europa medieval com o mundo árabe e islâmico, em especial na Península Ibérica, espaço de interação entre as três religióes monoteístas: cristianismo, islamismo e judaísmo. Em termos mais específicos, observa-se que a versão seleciona um conjunto de temáticas ou "conhecimentos históricos” que, na ausência de uma terminologia melhor, serão classificados como "conservadores".

Com essa expressão, busca-se remeter ao fato de o item se organizar em torno de elementos como: a formação do mundo medieval a partir da desestruturação e da fragmentação política romana; a referência da Igreja católica como detentora da primazia cultural e política do período; e a ênfase dada ao conceito de feudalismo, às três ordens, e ao espaço urbano, expresso no comércio, nas catedrais e nas universidades. É provável que, ao leitor em geral e mesmo aos formados em História que não tem proximidade com os estudos medievais, os conteúdos citados sejam solidamente referendados e funcionem como "lugares comuns" que não demandam questionamentos, vide, por exemplo, sua cristalização nos livros didáticos nacionais. No entanto, a partir da medievalística, convém observar que os conteúdos reforçam a perspectiva de uma Idade Média como temporalidade europeia e reafirmam a ideia da sociedade medieval forjada na crise do Baixo Império Romano, marcada por poderes fragmentados, perspectiva na qual se fundamenta a recorrente referência à violência, à anarquia feudal e à ausência de autoridades públicas, elementos diretamente relacionados ao paradigma estatal moderno. Do mesmo modo, a opção ressalta uma Igreja detentora da cultura e deveras institucional, quiçá a "senhora feudal" ainda tão estudada no ensino de história (PEREIRA, 2017). Ademais, ao enfatizar um espaço urbano, comercial e letrado, e não mencionar, por exemplo, o mundo rural ou senhorial, a versão contribui para uma ideia desequilibrada do período e que tende a encarar a cidade como antítese do feudalismo, ao passo que destaca no conteúdo obrigatório o estudo do conceito de feudalismo, uma questão deveras controversa na historiografia 5 .

Em linhas gerais, os conteúdos relativos à Idade Média parecem não encontrar correspondência nas discussões historiográficas pós-1980, tanto no âmbito internacional como no nacional, o que resulta numa seleção de conteúdos de matriz político-institucional e econômico-social, marcantes 
até a primeira metade do século passado ${ }^{6}$. A Idade Média na segunda versão da BNCC permanece encarada como período obscuro, uma idade intermediária, condicionada pelos referenciais da modernidade 7 . Observa-se a manutenção das oposições recorrentes nas abordagens sobre o medievo, como: comunidade ou coletividade/individualismo; ruralidade/urbanidade; cultura oral/cultura escrita; opressão/liberdade; entre outros. Do mesmo modo, a Base reafirma elementos como Estado, Violência e Igreja como eixos explicativos do período, aspectos que, para a medievalística atual, são considerados como falsas concepçóes acerca da Idade Média ${ }^{8}$. Em termos pedagógicos, a BNCC História opta por estruturar o currículo numa lista de conteúdo, resultando na recuperação de conteúdos tradicionais da História Medieval, talvez numa proposta de oferecer uma visão ampla de "toda a história”, mas que culmina na redução do medievo à Europa e, em especial, aos processos históricos ocorridos na França, Inglaterra, Alemanha e Itália.

De todo modo, no que pese o tom “conservador”, a segunda versão da BNCC também indica o êxito da mobilização dos profissionais de História Antiga e Medieval no sentido de ao menos garantir a presença da área nos itens obrigatórios da Base. Tal mobilização passou pela elaboração de diferentes documentos, como a Carta Norte e Nordeste (LIMA, 2015), a Carta da Abrem (ABREM, 2015), a Carta do NEMED (NEMED, 2015) e a Carta do Fórum dos Profissionais de História Antiga e Medieval (RJ) (FÓRUM..., 2016), além de resultar na inserção do Prof. Alexandre Moraes (UFF) como representante de História Antiga e Medieval nas reunióes que ocorreram no MEC, em março de 2016. Apesar disso, é perceptível a redução das manifestaçóes individuais e coletivas de medievalistas brasileiros desde a publicação da segunda versão da BNCC, o que pode estar relacionado ao retorno dos conteúdos de História Medieval para a Base, quiçá o principal objetivo imediato da mobilização; ao cenário político nacional, marcado pelo processo de impeachment presidencial da presidente Dilma Rousseff, ocorrido entre dezembro de 2015 e agosto de 2016, que passou a aglutinar as atenções dos historiadores em geral e deixou o tema da BNCC em segundo plano; ou à própria desmobilização dos professores em torno da questão da presença do medievo no currículo escolar nacional, um tema de crescente preocupação no meio acadêmico, mas que ainda ocupa um espaço secundário nas investigações dos medievalistas brasileiros.

Lançada em 6 de abril de 2017, a terceira e última versão da BNCC apresentou-se com a proposta de complementar e revisar a segunda versão. O documento foi encaminhado ao Ministro da Educação, Mendonça Filho, e ao Conselho Nacional de Educação (CNE), responsáveis pela elaboração de um parecer e de um projeto de resolução antes da homologação da Base, que ocorreu em dezembro de 2017. Acrescenta-se que o texto versava apenas sobre o Ensino Fundamental, visto que a Reforma do Ensino Médio seguiu em outros espaços.

A Diretoria da ANPEd manifestou-se contrária à terceira versão da BNCC, destacando cinco diferentes preocupações:

- A BNCC é um documento inspirado em experiências de centralização curricular, tal como o modelo do Common Core Americano, o Currículo Nacional desenvolvido na Austrália, e a reforma curricular chilena - todas essas experiências amplamente criticadas em diversos estudos realizados sobre tais mudanças em cada um desses países;

- A retirada do Ensino Médio do documento fragmentou o sentido da integração entre os diferentes níveis da Educação Básica, ao produzir centralização específica na Educação Infantil e Ensino Fundamental; 
- É preocupante também a retomada de um modelo curricular pautado em competências. Esta "volta" das competências ignora todo o movimento das Diretrizes Curriculares Nacionais construídas nos últimos anos e a crítica às formas esquemáticas e não processuais de compreender os currículos;

- A retirada de menções à identidade de gênero e orientação sexual do texto da BNCC reflete seu caráter contrário ao respeito à diversidade e evidencia a concessão que o MEC tem feito ao conservadorismo no Brasil;

- A concepção redutora frente aos processos de alfabetização e o papel da instituição escolar na educação das crianças (ANPEd, 2017, p. 1).

A partir da nota da ANPEd, nota-se que a conclusão e aprovação da Base ocorreram sob críticas diversas que abordam desde a concepção de currículo e o modelo curricular pautado na pedagogia das competências, aos conteúdos ou ênfases que foram suprimidas do documento, com destaque para as discussóes de gênero. Especificamente sobre o componente curricular História, Pereira e Rodrigues afirmam:

Importa, portanto, reconhecer dois elementos centrais que fazem parte dessa versão: o primeiro diz respeito ao modelo curricular conhecido como lista de conteúdos, o que se pôde observar já na segunda versão; o segundo [...] diz respeito ao modo como esse currículo proposto ao ensino de história trabalha a temporalidade e constrói narrativa a partir dele, na sua relação "prática” com o passado (PEREIRA; RODRIGUES, 2018, p. 11).

Deste modo, a Base reafirma a opção pela lista de conteúdos, viés presente na segunda versão e que tinha sido alvo de críticas, e parece tornar a aula de História um "microlaboratório da história profissional”, distanciando-se dos conflitos e lutas sociais, perspectiva que, para os autores, resulta no esvaziamento do potencial crítico da disciplina em relação às identidades dominantes e/ou tradicionais.

Em relação aos conteúdos de História Medieval, a revisão proporcionou uma mudança significativa. Como se observa no quadro abaixo, a versão divide-se em unidades temáticas, objetos de conhecimento e habilidades. As unidades temáticas constituem o grande eixo estruturante, mostrando-se bastantes flexíveis nos demais itens. A Idade Média permanece sendo estudada no 6o ano do Ensino Fundamental e a abordagem sugere uma maior aproximação da história social e, principalmente, da história cultural, ressaltando aspectos como: formas de contato entre populações, dinâmicas de circulação de pessoas e produtos, formas de organização do trabalho e da vida social, o papel cultural da religião cristã e os papéis sociais das mulheres. 
Quadro 4 - Unidades temáticas relativas à Idade Média na 3ª versão da BNCC.

\begin{tabular}{|c|c|c|c|}
\hline Ano & Unidades Temáticas & Objetos de Conhecimento & Habilidades \\
\hline \multirow[t]{8}{*}{ 6o ano } & \multirow[t]{3}{*}{$\begin{array}{l}\text { Lógicas de organização } \\
\text { política }\end{array}$} & $\begin{array}{l}\text { A passagem do mundo antigo } \\
\text { para o mundo medieval; }\end{array}$ & \multirow{2}{*}{$\begin{array}{l}\text { (EF06HI14) Identificar e analisar } \\
\text { diferentes formas de contato, } \\
\text { adaptação ou exclusão entre } \\
\text { populaçóes em diferentes } \\
\text { tempos e espaços. }\end{array}$} \\
\hline & & $\begin{array}{l}\text { A fragmentação do poder } \\
\text { político na Idade Média; }\end{array}$ & \\
\hline & & $\begin{array}{l}\text { O Mediterrâneo como espaço } \\
\text { de interação entre as sociedades } \\
\text { da Europa, da África e } \\
\text { do Oriente Médio. }\end{array}$ & $\begin{array}{l}\text { (EF06HI15) Descrever as dinâmicas } \\
\text { de circulação de pessoas, produtos e } \\
\text { culturas no Mediterrâneo } \\
\text { e seu significado. }\end{array}$ \\
\hline & \multirow{5}{*}{$\begin{array}{l}\text { Trabalho e formas de } \\
\text { organização social } \\
\text { e cultural }\end{array}$} & $\begin{array}{l}\text { Senhores e servos no mundo antigo } \\
\text { e no medieval; }\end{array}$ & \multirow{3}{*}{$\begin{array}{l}\text { (EF06HI16) Caracterizar e compa- } \\
\text { rar as dinâmicas de abastecimento } \\
\text { e as formas de organização do } \\
\text { trabalho e da vida social em } \\
\text { diferentes sociedades e períodos, } \\
\text { com destaque para as relações } \\
\text { entre senhores e servos. } \\
\text { (EF06HI17) Diferenciar escravidão, } \\
\text { servidão e trabalho livre no mundo } \\
\text { antigo. }\end{array}$} \\
\hline & & $\begin{array}{l}\text { Escravidão e trabalho livre em dife- } \\
\text { rentes temporalidades e espaços } \\
\text { (Roma Antiga, Europa } \\
\text { medieval e África); }\end{array}$ & \\
\hline & & $\begin{array}{l}\text { Lógicas comerciais na Antiguidade } \\
\text { romana e no mundo medieval; }\end{array}$ & \\
\hline & & $\begin{array}{l}\text { O papel da religião cristã, dos } \\
\text { mosteiros e da cultura na Idade } \\
\text { Média; }\end{array}$ & $\begin{array}{l}\text { (EF06HI18) Analisar o papel } \\
\text { da religião cristã na cultura e nos } \\
\text { modos de organização social } \\
\text { no período medieval. }\end{array}$ \\
\hline & & $\begin{array}{l}\text { O papel da mulher na Grécia } \\
\text { e em Roma, e no período medieval. }\end{array}$ & $\begin{array}{l}\text { (EF06HI19) Descrever e analisar } \\
\text { os diferentes papéis sociais das } \\
\text { mulheres no mundo antigo e } \\
\text { nas sociedades medievais. }\end{array}$ \\
\hline
\end{tabular}

Fonte: Elaborado pelo autor com base em Brasil (2017b, p. 418-419).

Buscando uma comparação entre as versões da Base, observa-se que os conteúdos de Idade Média conheceram uma variação marcante. Inicialmente inserida de forma lacunar em poucos itens, a História Medieval passou a ocupar espaço de destaque nos conhecimentos históricos esperados para o 60 ano, demarcando-se por uma abordagem conservadora e conteudista, ao passo que na terceira e última versão, passa-se a eixos amplos que estruturam o 6o ano do Ensino Fundamental em torno da Antiguidade Clássica e de uma Idade Média mediterrânea pensada por uma abordagem sociocultural. 
Quadro 5 - A Idade Média nas três versões da BNCC (2015-2017).

\begin{tabular}{|c|c|}
\hline Versão & Itens sobre Idade Média \\
\hline 1a versão & $\begin{array}{l}\text { (CHHI6FOA66) Conhecer e reconhecer diversas maneiras de contagem e registro do tempo } \\
\text { - calendários e formas consagradas -, dos astecas, dos maias, dos egípcios, dos diferentes } \\
\text { povos indígenas brasileiros, entre outros, discutindo usos e adequaçôes. } \\
\text { (CHHI6FOA71) Conhecer e problematizar as diferentes formas de periodização dos proces- } \\
\text { sos históricos tais como o modelo quadripartite francês (Idade Antiga, Idade Média, Idade } \\
\text { Moderna e Idade Contemporânea), identificando como o Brasil se insere nesta periodização. } \\
\text { (CHHI6FOA072) Identificar e discutir características, pessoas, instituiçóes, ideais e acon- } \\
\text { tecimentos relativos a cada um desses períodos históricos: Idade Antiga, Idade Média, Idade } \\
\text { Moderna e Idade Contemporânea. }\end{array}$ \\
\hline $2^{a}$ a versão & $\begin{array}{l}\text { (EF06HI16) Reconhecer as origens do Islamismo na Península Arábica no século VIII. } \\
\text { (EF06HI17) Compreender a desestruturação do Império Romano e a formação do mundo } \\
\text { medieval na Europa. } \\
\text { (EF06HI19) Identificar aspectos do conceito de feudalismo. } \\
\text { (EF06HI20) Identificar a fragmentação do poder político e a primazia cultural e política da } \\
\text { Igreja católica. } \\
\text { (EF06HI21) Classificar a estrutura da sociedade feudal definida a partir de três ordens, dos } \\
\text { oratores, bellatores e laboratores, representadas pelas figuras do sacerdote, do cavaleiro e do } \\
\text { camponês. } \\
\text { (EF06HI22) Identificar o papel do comércio e das cidades na Idade Média. } \\
\text { (EF06HI23) Identificar aspectos de manifestações culturais e artísticas do mundo medieval, } \\
\text { destacando a construção das catedrais, de castelos e o nascimento da Universidade. } \\
\text { (EF06HI24) Analisar e problematizar o conceito de Idade Média como periodização da His- } \\
\text { tória Universal. } \\
\text { (EF06HI25) Estabelecer as relações do mundo medieval com o mundo árabe, com o Império } \\
\text { Otomano e com as populaçôes judias. } \\
\text { (EF06HI26) Compreender o papel da biblioteca de Alexandria, das Cruzadas e da presença } \\
\text { de judeus e árabes na Península Ibérica. } \\
\text { (EF06HI27) Conhecer marcos fundamentais das Histórias Antiga e Medieval, incluindo } \\
\text { contraposiçóes, conexóes e trocas que se estabeleceram entre "Ocidente” e "Oriente” ao longo } \\
\text { desses séculos (cerca de } 3 \text { mil a.C. a fins do século XV). } \\
\text { (EF06HI28) Produzir textos que discorram sobre o desenvolvimento dessas civilizações e } \\
\text { sociedades. } \\
\text { (EF06HI29) Identificar diferentes fontes de conhecimento sobre as cidades medievais. } \\
\text { (EF06HI30) Compreender a noção de “era cristã”. }\end{array}$ \\
\hline 3a versão & $\begin{array}{l}\text { (EF06HI14) Identificar e analisar diferentes formas de contato, adaptação ou exclusão entre } \\
\text { populações em diferentes tempos e espaços. } \\
\text { (EF06HI15) Descrever as dinâmicas de circulação de pessoas, produtos e culturas no Mediter- } \\
\text { râneo e seu significado. } \\
\text { (EF06HI16) Caracterizar e comparar as dinâmicas de abastecimento e as formas de organi- } \\
\text { zação do trabalho e da vida social em diferentes sociedades e períodos, com destaque para as } \\
\text { relaçốes entre senhores e servos. } \\
\text { (EF06HI17) Diferenciar escravidão, servidão e trabalho livre no mundo antigo. } \\
\text { (EF06HI18) Analisar o papel da religião cristã na cultura e nos modos de organização social } \\
\text { no período medieval. } \\
\text { (EF06HI19) Descrever e analisar os diferentes papéis sociais das mulheres no mundo antigo e } \\
\text { nas sociedades medievais. }\end{array}$ \\
\hline
\end{tabular}

Fonte: Elaborado pelo autor com base em Brasil (2015, p. 243; 2016, p. 466, 468, 470, 472; 2017b, p. 418-419). 
A partir da homologação da Base, o Ministério da Educação estabelecerá um calendário de implementação da BNCC nos currículos dos estados e municípios, na elaboração nos materiais didáticos e na estruturação dos cursos de formação de professores, de pedagogia e de licenciaturas. Segundo Maria Helena de Castro, secretária-executiva do MEC, essa fase levará ainda cerca de dois anos (ANNUNCIATO, 2017).

A Base é uma referência nacional que indica conhecimentos esperados de todos os estudantes do país. Compreendendo que todo currículo, e, no caso específico deste artigo, o currículo de História, é um produto de escolhas e disputas, a BNCC expressa os embates em torno do que deve ser recortado e considerado do passado?. Ao apontar para a ruptura com o modelo eurocêntrico quadripartite de História, a primeira versão acabou por invisibilizar os conteúdos acerca da antiguidade e do medievo. A segunda e a terceira versão, ainda que com abordagens diferentes, optaram por um viés conteudista, que recolocou a sociedade medieval no currículo obrigatório. Como exposto, a Idade Média foi contemplada no texto da Base, porém apenas no 6o ano do Ensino Fundamental, numa faixa etária média entre 10 e 12 anos, sendo a maior parte da História Antiga limitada ao Ensino Fundamental - Anos Iniciais, no 5o ano, espaço que, tradicionalmente, não é ocupado por professores licenciados em História ${ }^{10}$. Num cenário de congelamento dos investimentos na Educação, de frequente contingenciamento de despesas, de ênfase na formação de professores através de cursos de licenciaturas, quais serão as consequências das proposições presentes na BNCC para a área de História Antiga e de História Medieval, já que uma das políticas decorrentes da Base é a Política Nacional de Formação de Professores? Esse é um questionamento que apenas os próximos anos responderão, todavia convém apresentar, brevemente, alguns apontamentos sobre o ensino de história medieval a partir dos elementos presentes na BNCC.

\section{História Medieval e ensino de história}

A possibilidade de elaboração de balanços bibliográficos acerca da medievalística brasileira constitui relevante indício do fortalecimento da História Medieval no país ${ }^{11}$. A trajetória de promoção do campo no meio acadêmico nacional recua, sobretudo, ao período de 1980 e 1990, mas é possível buscar as raízes institucionais da medievalística brasileira em períodos mais recuados, em especial na década de 1930, com a cátedra de História da Civilização Antiga e Medieval da Faculdade de Filosofia, Ciências e Letras da Universidade de São Paulo, e a atuação de uma tríade de pioneiros: Eurípedes Simões de Paula - que em 1942 viria a defender a primeira tese brasileira dedicada ao medievo -, Eduardo d'Oliveira França e Pedro Moacyr Campos (MIATELLO, 2017).

Ambos os caminhos de reconstituição histórica da trajetória da medievalística brasileira apontam que a área acompanhou o desenvolvimento institucional do próprio campo de História no Brasil, por exemplo, com a multiplicação de programas de pós-graduação, o aumento do financiamento e a ampliação do número teses, dissertações e estudos especializados publicados em língua portuguesa. Não obstante, é possível traçar duas linhas interpretativas, uma que compreende os inegáveis avanços da medievalística brasileira nas últimas décadas e outra que lembra as importantes resistências ainda enfrentadas, as quais, por vezes, questionam a própria existência do campo ou as contribuiçóes que tal estudo poderia dar ao conhecimento histórico das novas gerações no Brasil (LIMA, 2019). 
Apesar das resistências e dos desafios impostos aos estudos medievais, mostra-se premente conciliar a erudição alcançada pelas pesquisas no país com uma comunicação social e uma inserção social mais efetiva. Tal demanda tem se acentuado nos últimos anos, e em especial, desde a publicação da primeira versão da Base Nacional Comum Curricular. A despeito disso, a área de História Medieval tem buscado reafirmar a relevância do medievo para o ensino de história, e, entre 2016 e 2017, um conjunto de artigos de medievalistas brasileiros foi publicado abordando a temática do ensino de história medieval e da BNCC, dos quais se destacam alguns apontamentos no intuito de apresentar os caminhos do debate no cenário nacional.

No artigo $A$ Idade Média nos currículos escolares: as controvérsias nos debates sobre a BNCC (2016), os professores Igor Salomão Teixeira e Nilton Mullet Pereira, da Universidade Federal do Rio Grande do Sul, ressaltam o crescimento dos estudos medievais no Brasil e o interesse dos estudiosos da área em discutir sobre o ensino escolar de história medieval. Os autores propóem:

[...] tomar a crítica aos textos da BNCC, considerando a importância que teve a versão preliminar, porque é significativa para o estudo dos temas medievais na sala de aula, a quebra importante levada a efeito pelo documento em relação a uma história quadripartite, que tem como referência a Revolução Francesa e, ao mesmo tempo, o tanto de medievalidade que se encontrou na segunda versão da Base. Pretendemos salientar a defesa realizada pela ABREM, que considera o estudo de um passado como a Idade Média em função do encantamento que desperta nos estudantes, pelas relações de pertencimentos que permite estabelecer entre esse passado e a realidade dos alunos ou mesmo pelos motivos da criação de uma cultura política. No entanto, pretendemos, também, ampliar essa tripla leitura que a Associação utiliza para defender a Idade Média nos currículos escolares. A proposta é pensar sobre processos de estranhamento necessários tanto à aprendizagem história dos estudantes, quanto à formação política das novas geraçóes (TEIXEIRA; PEREIRA, 2016, p. 20).

Os autores são enfáticos em afirmar que a primeira versão da Base teve como pontos altos o não privilégio à história europeia e sua crítica ao eurocentrismo e ao modelo quadripartite, permitindo uma profícua discussão sobre a aprendizagem histórica. Ao optarem por demarcar esta posição, demonstram que a Idade Média também pode ser pensada como um conteúdo crítico à monocultura do saber, em diálogo, e não em oposição, com os estudos africanistas e indigenistas, por exemplo, que ressaltam a inclusão das discussões pós-coloniais no ensino de história ${ }^{12}$. Outrossim, defendem que a segunda versão representa um recuo a abordagens históricas conservadoras, sendo duramente criticada por manter "os preconceitos iluministas acerca da Idade Média" e "demonstrar desatualização em relação à pesquisa sobre o medievo no Brasil e no Mundo, revelando desse modo um conjunto de estereótipos já desconstituídos pela medievalistica" (TEIXEIRA; PEREIRA, 2016, p. 24). Igor Teixeira e Nilton Pereira avançam ainda em reflexóes sobre o potencial da Idade Média para a formação das novas gerações, centrando-se na questão dos usos do passado e mobilizando elementos da medievalística, das reminiscências medievais e da medievalidade.

Em 2017, a Revista Chilena de Estudios Medievales lançou dossiê dirigido por Marcelo Cândido da Silva que discute os desafios da História Medieval na América Latina. Do conjunto de artigos do dossiê, destacam-se dois trabalhos. Em primeiro lugar, assinala-se a contribuição de Cláudia Bovo, no artigo El tiempo en cuestión: ubicar la Edad Media en la actualidad. A autora parte da significativa popularidade atual da Idade Média para tecer sua reflexão acerca dos usos públicos do período, apontamentos que tanto problematizam o lugar da História Medieval como campo 
da História, como discutem a contribuição da Idade Média para o ensino de história. Ao tratar da educação básica, Bovo afirma:

Así, al menos en lo que se dice con respecto respecto a la realidad escolar brasileña, el vaciamiento teórico de la historia escolar, la nefasta división entre dicho contenido histórico y la investigación histórica han dado lugar a la incapacidade para hacer de este encuentro de diferentes relatos históricos intencionales y problemáticos por el sesgo de la historia disciplinar. No estamos preparando a los jóvenes a pensar históricamente. [...]

El dominio sobre la temporalidad, sobre los recursos que contextualizan el forjar del tiempo histórico están ocultos en la enseñanza de la historia escolar. Aprender a pensar históricamente todavía implica en un tipo de actividad intelectual que es conceptual. Definir la historia envuelve especificar los procedimentos sujetos a su constitución en cuanto área de conocimiento y el establecimiento supone que todo sujeto de aprendizaje está constituido históricamente (BOVO, 2017, p. 151, 153).

Ao criticar o ensino de história no Brasil pelas dificuldades de os estudantes pensarem historicamente, compreendendo a formação do tempo histórico e as especificidades da História como área de conhecimento, Bovo ressalta a importância do medievo para superar esse quadro. Ao enfatizar que a Idade Média não existe e que é necessário transmitir tal percepção ao público não acadêmico, a autora demonstra que a Idade Média contribui para evidenciar a artificialidade dos mecanismos de periodização e como o tempo pode ser forjado para enfatizar rupturas e continuidades. Outrossim, Bovo explora uma problemática deveras recorrente nos debates acerca do ensino de história, o papel da disciplina para a relação identidade/alteridade, ressaltando que o uso do conhecimento histórico na vida prática se dá através da compreensão da identidade histórica e da capacidade do ser humano atribuir significado ao tempo, o que pode estar relacionado à própria experiência ou a de tempos recuados, como a Idade Média (BOVO, 2017).

O segundo artigo do referido dossiê a ser assinalado é o trabalho de Néri de Barros Almeida, Um destino em crise: a inserção social e institucional dos estudos História Medieval (2017). O texto dá especial atenção ao consistente crescimento em número e qualidade da área de História Medieval no Brasil, contudo sublinha que a primeira versão da BNCC lançou o alerta de que a área não era plenamente reconhecida no meio acadêmico nacional. Sem propor uma reflexão sobre a versão, a autora defende a necessária "inserção acadêmica e social dos resultados de pesquisa da área, o que implica de saída em projetos interáreas e na diversificação da natureza das publicações hoje ainda muito voltadas para o público especializado" (ALMEIDA, 2017, p. 96). Em outro momento do texto, Almeida volta a propor que "incluamos em nosso horizonte atividades de alcance social mais significativo e para isso é preciso que adotemos a reflexão sobre o que escrever e como escrever como parte de nossa atividade profissional permanente" (ALMEIDA, 2017, p. 99). A autora reafirma a ideia de uma Idade Média plural e a importância de se pensar tanto "como a Idade Média se torna europeia e o que isso representa", como "a reincorporação de toda a bacia do Mediterrâneo à representação da Idade Média” (ALMEIDA, 2017, p. 105). Ademais, Almeida ressalta elementos que favorecem o estudo do medievo a partir do Brasil, como a perspectiva distanciada, que resulta em abordagens supranacionais e supraeuropeias do período, e a vocação para a pluralidade, manifesta na diversificação das pesquisas no país. Ao concluir seus apontamentos sobre o cenário de "crise" dos estudos medievais, a autora defende que 
[é] preciso que iniciativas interáreas que contemplem esses três domínios (teórico-metodológico, historiográfico, temático) sejam valorizadas, da mesma forma que, com sua voz própria, os estudos medievais se ocupem de intervir publicamente perseguindo o outro extremo da especialização: a produção de sínteses amplas originais de obras específicas que dialoguem com as questóes que inquietam as pessoas de hoje (ALMEIDA, 2017, p. 111).

Uma Idade Média plural que questiona a referência europeia. Quiçá, tal reivindicação expresse um dos principais desafios postos aos estudos medievais e à história medieval no Brasil, especialmente no que tange à Educação Básica. Nesse sentido, Nilton Pereira e Mara Rodrigues apresentam diferentes contribuições, ainda que a questão da Idade Média não seja o eixo da reflexão dos autores. Como demonstram, desde a publicação da primeira versão da BNCC as "disputas se deram sobretudo no campo da legitimidade do legado de uma ou outra formação histórica para a constituição da identidade brasileira”, enfatizando as continuidades estabelecidas entre um passado europeu, africano ou indígena com a atualidade (PEREIRA; RODRIGUES, 2018, p. 6). De fato, desde o estabelecimento da cátedra de História Medieval em meados do século passado foram mobilizados diferentes argumentos no intuito de justificar o campo, dentre eles, o principal foi o tema das "sobrevivências/heranças medievais", que estariam presentes nas mentalidades, na cultura ou ainda nos elementos socioeconômicos, uma herança que justificaria sobretudo a pesquisa acerca da história medieval da Península Ibérica e da história medieval portuguesa. Por exemplo, Ruy Afonso da Costa Nunes, em seu clássico manual História da Educação na Idade Média, lançado em 1979, afirmava que

a Idade Média europeia é um período histórico a ser devidamente considerado como qualquer outro; mas particularmente importante para nós brasileiros, uma vez que o Brasil foi descoberto e colonizado pelos portugueses no fim da Idade Média e de Portugal herdou a religião, as tradições culturais e os costumes de tal modo que, apesar das contribuições indígenas e africanas, o núcleo da brasilidade é legado europeu e lusitano. As nossas tradiçóes escolares, por exemplo, são de ascendência portuguesa e jesuítica e, assim, de origem rigorosa e classicamente medieval (NUNES, 2018, p. 29-30).

Por caminhos distintos e reivindicando a necessária descolonização da Idade Média, José Rivair Macedo, num dos principais textos sobre o ensino de história medieval no Brasil, afirmou:

Desse modo, repensar o ensino da Idade Média implica, em primeiro lugar, na reflexão sobre a propriedade de continuarmos a transferir conhecimentos relativos a uma Europa que, na verdade, se restringe à parte ocidental (França, Inglaterra, Alemanha, Itália) daquele continente, mantendo em segundo plano os dados relativos ao Norte (países escandinavos), o Leste (países eslavos) e a Península Ibérica (Portugal e Espanha). Para nós, faz muito sentido compreender a formação dos povos ibéricos, pois isso nos permite compreender melhor nossas características herdadas, parte de nosso modo de ser e de pensar. [...] A ênfase no ensino dos aspectos históricos da Península Ibérica teria muito mais propriedade educativa do que o ensino da História modelada na França ou na Inglaterra, pelo simples fato de pertencermos a um conjunto cultural específico, no caso, o ibero-americano. Ao tomar a Península Ibérica como núcleo gerador da consciência histórica a respeito da Idade Média, o ensino de História cumpriria melhor o seu papel de revelar aos estudantes aspectos do nosso passado que continuam a interagir com o presente (MACEDO, 2008, p. 115-116). 
Tendo em vista a importância e a longevidade da perspectiva da identidade na percepção da História no Brasil e mesmo na referência dos estudos medievais no país, convém pensar: como trabalhar a identidade sem olhar para o que é diferente? Para Nilton Pereira e Mara Rodrigues (2018), a alteridade pode passar pelo estudo das temporalidades europeias, importando "descolonizar" não apenas os conteúdos, mas as abordagens narrativas e os objetivos do ensino de história. Quiçá, seja esse um dos potenciais caminhos a serem trilhados pelos medievalistas brasileiros no âmbito do ensino de história.

\section{Considerações finais}

Como pensar a História Medieval no ensino de história? A área caracteriza-se atualmente por uma produção sólida e de expressão internacional, com a defesa de inúmeros trabalhos de pós-graduação, com a organização de eventos, periódicos e associações especializadas, contudo pesa sobre o campo uma série de desconfianças, as quais, por vezes, manifestam-se na constante necessidade de justificação dos estudos antigos e medievais no Brasil. A BNCC publicizou a contestação e fez sobressair diferentes aspectos do problema.

Ao combater pela permanência da Idade Média no currículo obrigatório da Educação Básica, os historiadores mobilizaram uma série de argumentos, dentre os quais, reafirmou-se a perspectiva identitária das raízes medievais/ocidentais do Brasil, uma via que favorece o acesso ao medievo ibérico e cristão, mobilizando, por vezes, um viés tradicional de abordagem do conteúdo de Idade Média, que compreende o período condicionado aos paradigmas políticos e sociais da modernidade, como se apresentou na segunda versão da Base. Paralelamente, os medievalistas também se propuseram a criticar a Base Nacional Comum Curricular defendendo que a Idade Média fosse repensada no ensino de história, incorporando a pluralidade cultural do período, descentralizando o medievo da experiência europeia ocidental, incluindo novos grupos sociais e abordando os usos contemporâneos do passado medieval. Tal via, em diálogo com as discussóes da teoria pós-colonial, da história global e do medievalismo, tem demonstrado o potencial pedagógico da Idade Média, seja pelo viés da identidade, seja pela alteridade.

Não obstante, essas reflexões são questóes em aberto e em debate na historiografia, ao passo que os próprios resultados práticos da BNCC, como a reformulação dos cursos de licenciatura e dos materiais didáticos, por exemplo, ainda são uma história do porvir. Todavia, em meio a todos os percalços a Idade Média confirmou-se como um dos conteúdos obrigatórios para o ensino de história, sendo inserida apenas no 6o ano do Ensino Fundamental, através de uma lista de conteúdos de abordagem sociocultural voltados ao eixo do Mediterrâneo. Assim, prevê-se que o estudante terá contato com a História Medieval entre os 10 e 12 anos de idade, estudando a circulação de pessoas, a organização do trabalho e da vida social, o papel da religião cristã e das mulheres na sociedade medieval. Como abordar? Quais materiais usar ou quais materiais didáticos estão disponíveis? Novos desafios aos historiadores de hoje e de amanhã.

\section{Referências}

ALMEIDA, Néri de Barros. Um destino em crise: a inserção social e institucional dos estudos de História Medieval. Revista Chilena de Estudios Medievales, Santiago, n. 11, p. 92-114, enero/jun. 2017. 
ANNUNCIATO, Pedro. Da terceira versão à sala de aula: os próximos passos da Base Nacional Comum. Nova Escola, São Paulo, 6 abr. 2017. Disponível em: https://novaescola.org.br/conteudo/4872/da-terceiraversao-a-sala-de-aula-os-proximos-passos-da-base-nacional-comum. Acesso em: 27 out. 2018.

ASSOCIAÇÃO BRASILEIRA DE ESTUDOS MEDIEVAIS (ABREM). Carta da Associação Brasileira de Estudos Medievais (ABREM) sobre a BNCC. Niterói, RJ, 11 dez. 2015. Disponível em: https://anpuh.org.br/index.php/ bncc-historia/item/3158-carta-da-associacao-brasileira-de-estudos-medievais-sobre-a-bncc. Acesso em: 27 out. 2018

ASSOCIAÇÃO NACIONAL DE HISTÓRIA (ANPUH); ASSOCIAÇÃO BRASILEIRA DE ESTUDOS AFRICANOS (ABE-África). Nota do GT de História da África da Anpuh Brasil e da Associação Brasileira de Estudos Africanos (ABE-África) sobre a proposta da Base Nacional Comum Curricular (BNCC) para o ensino de história. Rio de Janeiro, 26 de fevereiro de 2016. Disponível em: https://anpuh.org.br/index.php/bncc-historia/item/3322-nota-do-gt-de-historia-da-africa-da-anpuh-nacional-e-da-associacao-brasileira-deestudos-africanos-abe-africa-sobre-a-proposta-da-base-nacional-comum-curricular-bncc-para-oensino-de-historia. Acesso em: 27 out. 2018.

ASSOCIAÇÃO NACIONAL DE PESQUISADORES E PROFESSORES DE HISTÓRIA DAS AMÉRICAS (ANPHLAC). Nota da Anphlac sobre a Base Nacional Comum Curricular (BNCC). São Paulo, 23 dez. 2015. Disponível em: http://anphlac.fflch.usp.br/noticia_49. Acesso em: 27 out. 2018.

ASSOCIAÇÃO NACIONAL DE PÓS-GRADUAÇÃO E PESQUISA EM EDUCAÇÃO (ANPEd); ASSOCIAÇÃO BRASILEIRA DE CURRÍCULO (ABdC). Ofício n. 01/2015/GR. Rio de Janeiro: ANPEd; ABdC, 2015.

AUSTRALIAN CURRICULUM, ASSESSMENT AND REPORTING AUTHORITY (ACARA). Análise da Base Nacional Comum Curricular de História. Versão 2. Concluída pela Dra. Tracey McAskill. In: MOVIMENTO PELA BASE NACIONAL COMUM. Índice de insumos do Movimento pela Base. Brasil: Movimento pela Base Nacional Comum, [2016?]. Seção 7.2, p. 350-404.

BOVO, Cláudia. El tiempo en cuestión: ubicar la Edad Media en la actualidad. Revista Chilena de Estudios Medievales, Santiago, n. 11, p. 134-155, enero/jun. 2017.

BRASIL. Constituição da República Federativa do Brasil: texto constitucional promulgado em 5 de outubro de 1988. Brasília: Senado Federal, Coordenação de Edições Técnicas, 2017a.

BRASIL. Ministério da Educação. Secretaria da Educação Básica. Base Nacional Comum Curricular. Brasília, DF: MEC, 2015.

BRASIL. Ministério da Educação. Secretaria da Educação Básica. Base Nacional Comum Curricular. Brasília, DF: MEC, 2016.

BRASIL. Ministério da Educação. Secretaria da Educação Básica. Base Nacional Comum Curricular. Brasília, DF: MEC, 2017b.

CAIMI, Flávia Eloisa. A História na Base Nacional Comum Curricular: pluralismo de ideias ou guerra de narrativas? Revista do Lhiste, Porto Alegre, v. 3, n. 4, p. 86-92, jan./jun. 2016.

CANCIAN, Natália. Nova versão da base nacional curricular traz de volta história da Europa. Folha de São Paulo, Brasília, 3 maio 2016. Caderno Educação. Disponível em: https://www1.folha.uol.com.br/educacao/ 2016/05/1767444-nova-versao-de-base-curricular-altera-propostas-para-ensino-medio-e-infantil.shtml. Acesso em: 27 out. 2018.

FÓRUM DOS PROFISSIONAIS DE HISTÓRIA ANTIGA E MEDIEVAL. Carta de repúdio à BNCC produzida pelo Fórum dos Profissionais de História Antiga e Medieval. Rio de Janeiro, 26 nov. 2016. Disponível em: https:// anpuh.org.br/index.php/bncc-historia/item/3127-carta-de-repudio-a-bncc-produzida-pelo-forum-dosprofissionais-de-historia-antiga-e-medieval. Acesso em: 27 out. 2018.

GARCIA, Graciela et al. História da América e a BNCC. Rio de Janeiro, 3 dez. 2015. Disponível em: https:// anpuh.org.br/index.php/bncc-historia/item/3129-historia-da-america-e-a-bncc. Acesso em: 27 out. 2018.

LEITE, Pricilla Gontijo. Ensino de História, Reformas do Ensino e Percepções da Antiguidade: apontamentos a partir da atual conjuntura brasileira. Mare Nostrum, São Paulo, n. 8, 2017.

LIMA, Douglas Mota de. Carta de professores do Norte e Nordeste sobre a BNCC. [E-mail enviado à ANPUH e divulgado]. Destinatário: Thiago Reis [ANPUH-RJ]. Santarém, PA, 5 dez. 2015. 1 e-mail. Disponível em: https:// anpuh.org.br/index.php/bncc-historia/item/3149-carta-de-professores-do-norte-e-nordeste-sobre-a-bncc. Acesso em: 27 out. 2018. 
LIMA, Douglas Mota de. Uma história do porvir: a medievalística brasileira em terras amazônicas. In: AMARAL, Clínio; LISBÔA, João (org.). A historiografia medieval no Brasil: 1990 a 2017. Curitiba: Editora Prismas; Editora Appris, 2019. p. 61-90.

MACEDO, José Rivair. Repensando a Idade Média no Ensino de História. In: KARNAL, Leandro (org.). História na sala de aula: conceitos, práticas e propostas. São Paulo: Contexto, 2008. p. 109-125.

MIATELLO, André Luis Pereira. A História Medieval na graduação em História: da pesquisa à docência. Revista Chilena de Estudios Medievales, Santiago, n. 11, p. 68-90, enero/jun. 2017.

NÚCLEO DE ESTUDOS MEDITERRÂNICOS (NEMED). NEMED sobre a BNCC História especialmente o Ensino Médio. Curitiba, 30 nov. 2015. Disponível em: http://nemed.he.com.br/nemed-sobre-o-bncc-historia-especialmente-o-ensino-medio/. Acesso em: 27 out. 2018.

NUNES, Ruy Afonso da Costa. História da Educação na Idade Média. 2. ed. São Paulo: Kírion, 2018.

PEREIRA, Nilton Mullet. A invenção do medievo: narrativas sobre a Idade Média nos livros didáticos de história. In: ROCHA, Helenice; REZNIK, Luís; MAGALHÃES, Marcelo de Souza (org.). Livros didáticos de história: entre políticas e narrativas. Rio de Janeiro: FGV Editora, 2017. p. 169-184.

PEREIRA, Nilton Mullet; RODRIGUES, Mara Cristina de Matos. BNCC e o passado prático: temporalidades e produção de identidades no Ensino de História. Arquivos Analíticos de Políticas Educativas, Tempe, Arizona, v. 26 , n. 107 , set. 2018 .

TACLA, Adriene Baron; LIMA, Alexandre Carneiro Cerqueira. Um manifesto pela História e pelas experiências das culturas da Antiguidade. Rio de Janeiro, 2016. Disponível em: https://www.anpuh.org.br/index.php/ bncc-historia/item/3123-manifesto-do-gtha-sobre-a-bncc. Acesso em: 27 out. 2018.

TEIXEIRA, Igor Salomão; PEREIRA, Nilton Mullet. A Idade Média nos currículos escolares: as controvérsias nos debates sobre a BNCC. Diálogos, Maringá, PR, v. 20, n. 3, p. 16-29, 2016.

\section{Notas}

${ }^{1}$ A ANPEd lançou a campanha Aqui já tem currículo no intuito de demonstrar que os professores já praticam currículos plurais e não foram ouvidos pela Base. Para outras críticas gerais sobre o documento, ver: ASSOCIAÇÃO NACIONAL DE POLÍTICA E ADMINISTRAÇÃO DA EDUCAÇÃO (ANPAE). Comentários iniciais para a discussão do documento preliminar da Base Nacional Comum Curricular (BNCC). Goiânia, 2 nov. 2015. Disponivel em: https://www.anpae.org.br/website/ documentos/ANPAE-Doc-Preliminar-de-analise-da-BNCC-02-11-2015.pdf. Acesso em: 27 out. 2018; CONFEDERAÇÃO NACIONAL DE TRABALHADORES EM EDUCAÇÃO (CNTE). Considerações da CNTE sobre o Projeto de Base Nacional Curricular, elaborado preliminarmente pelo MEC. Revista Retratos da Escola, Brasília, v. 9, n. 17, p. 411-420, jul./dez. 2015

${ }^{2}$ Cf. ROCHA, Nathália Fernandes Egito; PEREIRA, Maria Zuleide da Costa. O que dizem sobre a BNCC? Produções sobre a Base Nacional Comum Curricular (BNCC) no período de 2010 a 2015. Espaço do Currículo, João Pessoa, v. 9, n. 2, p. 215-236, maio/ago. 2016.

${ }^{3}$ Uma defesa desta opção e as potencialidades da mesma para as reflexões em torno dos estudos pós-coloniais e descoloniais, das epistemologias do sul e da crítica ao eurocentrismo, podem ser vistas em: SILVA JÚNIOR, Astrogildo Fernandes da. BNCC, componentes curriculares de história: perspectiva de superação do eurocentrismo. EccoS Revista Científica, São Paulo, n. 41, p. 91-106, set./dez. 2016. Para uma crítica à perspectiva "brasiliocêntrica" e "patriótica" da primeira versão, ver: CALIL, Gilberto. Uma história para o conformismo e a exaltação patriótica: crítica à proposta de BNCC/História. Giramundo, Rio de Janeiro, v. 2, n. 4, p. 39-46, jul./dez. 2015.

${ }^{4}$ Conforme os dados indicados na BNCC, a equipe responsável foi apenas reduzida de catorze (14) membros para dez (10), não havendo inclusão de novos nomes, e, consequentemente, não houve alteração do perfil da comissão. Tais dados contrastam com a afirmação de Flávia Caimi, quando indica que "a comissão de doze profissionais que produziu a primeira versão da BNCC História foi dissolvida e em seu lugar constituída uma nova comissão, integrada predominantemente por profissionais vinculados a uma única instituição de Ensino Superior, cujas trajetórias de estudos e investigação não se mostram efetivamente vinculadas ao campo do ensino de história" (CAIMI, 2016, p. 90).

${ }^{5}$ Cf. REYNOLDS, Susan. Fiefs and vassals: the medieval evidence reinterpreted. Oxford: Oxford University Press, 1994; DAVIS, Kathleen. Periodization and Sovereignty: how ideas of Feudalism and Secularization govern the Politics of time. Philadelfia: University of Pennsylvania Press, 2008. 
${ }^{6} \mathrm{Cf}$. MURILO, Marcelo da Silva. A Idade Média nos livros didáticos brasileiros: a crise do século XIV, reverberações da historiografia acadêmica da primeira metade do século XX nos esquemas explicativos escolares. 2015. 314 f. Tese (Doutorado em História Social) - Faculdade de Filosofia, Letras e Ciências Humanas, Universidade de São Paulo, São Paulo, 2015.

${ }^{7}$ Cf. DAGENAIS, John; GREER, Margaret. Decolonizing the Middle Ages: introduction. Journal of Medieval and Early Modern Studies, Durham, v. 30, n. 3, p. 431-448, Fall 2000.

${ }^{8}$ Cf. HARRIS, Stephen; GRIGSBY, Bryon (ed.). Misconceptions about the Middle Ages. New York; London: Routledge, 2008.

${ }^{9}$ Nas últimas décadas são crescentes as investigações acerca do currículo, formando, inclusive, um campo de pesquisas acerca da temática. Assinala-se que o currículo é "um campo de batalha”, que expressa lutas corporativas, políticas, econômicas, de identidade, culturais etc. Ele é um artefato social e cultural, implicado em relações de poder e que transmite visões sociais particulares e interessadas, produzindo identidades individuais e sociais particulares. Em relação às discussões acerca do currículo, ver: MOREIRA, António Flávio; TADEU, Tomaz (org.). Currículo, cultura e sociedade.12. ed. São Paulo: Cortez, 2013; SACRISTÁN, José Gimeno (org.). Saberes e incertezas sobre o currículo. Tradução Alexandre Salvaterra. Porto Alegre: Penso, 2013.

${ }^{10}$ Os cursos de graduação em Pedagogia oferecem disciplinas voltadas a todas as áreas do conhecimento e componentes curriculares específicos para o ensino de História que, por exemplo, abordam as escolas historiográficas, a relação do historiador com os documentos, a didática da história e dimensões da história. Contudo, assinala-se que a inclusão da história Antiga no $5^{\circ}$ ano, com a referência à hominização e aos processos históricos do Egito e da Mesopotâmia, por exemplo, afasta-se dos elementos tradicionalmente discutidos nessas séries (noções de tempo, história local, documentos, etc.) e da formação de História oferecida aos pedagogos.

${ }^{11}$ Existe um número relevante de artigos que se dedicaram a fazer um balanço dos estudos medievais no Brasil. Desta maneira, limitamo-nos a indicar apenas alguns que poderão oferecer uma visão ampla acerca do tema e introduzir o leitor nos principais problemas relativos ao campo: ALMEIDA, Néri de Barros. A história medieval no Brasil. Revista Signum, v.14, n. 1, p. 1-16, 2013; AMARAL, Clínio; LISBÔA, João (org.). A historiografia medieval no Brasil: 1990 a 2017. Curitiba: Editora Prismas; Editora Appris, 2019; ASFORA, Wanessa; AUBERT, Eduardo; CASTANHO, Gabriel. Faire l'histoire du Moyen Âge au Brésil. Bulletin du Centre d'études médiévales d'Auxerre, Auxerre, v. 12, p. 125-144, 2008; FRANCO JÚNIOR, Hilário; BASTOS, Mario Jorge da Motta; RUST, Leandro Duarte. Historiographie et médiévistique brésilienne: une aproche d'ensemble. In: MAGNANI, Eliana (dir.). Le Moyen Âge vu d'ailleurs: voix croisées d'Amérique latine et d'Europe. Dijon: Editions Universitaires de Dijon, 2010. p. 39-52; MACEDO, José Rivair. Os estudos medievais no Brasil: tentativa de síntese. Reti Medievali Rivista, Verona, v. VII, n. 1, p. 1-9, genn./giugno 2006.

${ }^{12} \mathrm{O}$ artigo de Teixeira e Pereira (2016) serve de contraponto às críticas que consideram que a presença dos conteúdos de História Antiga e História Medieval na BNCC resultam numa perspectiva eurocêntrica, como em: CONCEIÇÃO, Maria Telvira da. O ocularcentrismo da Base Nacional Comum Curricular de História. Revista do Lhiste, Porto Alegre, v. 3, n. 4, p. 93-97, jan./jun. 2016.

Data de recebimento: 29/10/2018

Data de aprovação: 05/03/2019 